\title{
Pharmacokinetics of Diazepam and Its Metabolites in Urine of Chinese Participants
}

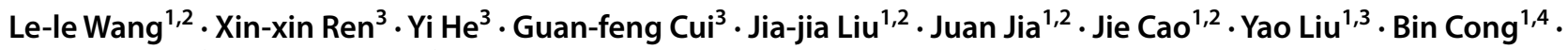 \\ Zhi-wen $\mathrm{Wei}^{1,2} \cdot$ Ke-ming Yun ${ }^{1,2}$
}

Accepted: 28 November 2021 / Published online: 31 January 2022

(c) The Author(s) 2022

\begin{abstract}
Background Urine is conventionally used as a specimen to document diazepam-related crimes; however, few reports have described the pharmacokinetics of diazepam and its metabolites in urine.

Objective This study aimed to investigate the pharmacokinetics of diazepam and its metabolites, including glucuronide compounds, in the urine of Chinese participants.

Methods A total of 28 volunteers were recruited and each participant ingested $5 \mathrm{mg}$ of diazepam orally. Ten milliliters of urine were collected from each participant at post-consumption timepoints of prior (zero), 1, 2, 4, 8, 12, and $24 \mathrm{~h}$ and 2 , $3,6,12$, and 15 days. All samples were extracted by solid-phase extraction and analyzed using high-performance liquid chromatography-tandem mass spectrometry. Diazepam and its main metabolites, except for temazepam, were detected in the urine of volunteers. Pharmacokinetic parameters were analyzed using the pharmacokinetic software DAS according to the non-compartment model.

Results Urinary diazepam peaked at $2.38 \mathrm{ng} / \mathrm{mL}\left(C_{\max }\right)$ and $1.93 \mathrm{~h}\left(T_{\max }\right)$. The urinary metabolite nordiazepam peaked at $1.17 \mathrm{ng} / \mathrm{mL}$ and $100.21 \mathrm{~h}$; temazepam glucuronide (TG) peaked at $145.61 \mathrm{ng} / \mathrm{mL}$ and $41.14 \mathrm{~h}$; and oxazepam glucuronide (OG) peaked at $101.57 \mathrm{ng} / \mathrm{mL}$ and $165.86 \mathrm{~h}$. The elimination half-life $\left(t_{1 / 2 z}\right)$ and clearance (CLz/F) for diazepam were 119.58 $\mathrm{h}$ and $65.77 \mathrm{~L} / \mathrm{h}$, respectively. The $t_{1 / 2 \mathrm{z}}$ of the metabolites nordiazepam, TG, and OG was $310.58 \mathrm{~h}, 200.17 \mathrm{~h}$, and $536.44 \mathrm{~h}$, respectively. Finally, this study found that both diazepam and its main metabolites in urine were detectable for at least 15 days, although there were individual differences.

Conclusion The results regarding diazepam pharmacokinetics in urine would be of great help in forensic science and drug screening.
\end{abstract}

Zhi-wen Wei

weizhiwen2000@163.com

Ke-ming Yun

yunkeming5142@163.com

1 School of Forensic Medicine, Shanxi Medical University, Jinzhong 030600, Shanxi, China

2 Key Laboratory of Forensic Toxicology of Ministry of Public Security, Jinzhong 030600, Shanxi, China

3 Institute of Forensic Science, Ministry of Public Security, Beijing 100038, China

4 Department of Forensic Medicine, Hebei Medical University, Shijiazhuang 050017, China

\section{Key Points}

The pharmacokinetics of diazepam and its main metabolites, including phase II metabolites, in urine of 28 Chinese participants were investigated.

The obtained elimination half-lives of the phase II metabolites in urine were discovered for the first time and are useful for the identification of driving under the influence of diazepam in a Chinese population. 


\section{Introduction}

Diazepam is the most typical hypnotic for benzodiazepines. It has been widely used to treat central nervous system disorders such as anxiety, epilepsy, and alcohol withdrawal since the 1960s [1, 2]. However, many other major problems emerged, such as drug dependence and drug abuse, which finally led to an increasing number of forensic cases, such as suicide, drug-driving, and robbery [3-5].

Diazepam is metabolized to nordiazepam, temazepam, oxazepam, temazepam glucuronide (TG), and oxazepam glucuronide (OG) [6]. In the process of diazepam metabolism, the glucuronides were reported to represent $88 \%$ and $71.4 \%$ of the total temazepam and oxazepam in human urine, respectively [7], leading to lower concentrations of temazepam and oxazepam. The concentrations of temazepam are especially low.

Diazepam is metabolized through the liver and eliminated from the kidney. Therefore, urine is a conventional specimen used to document diazepam-related crimes. In addition, because of the convenience and non-invasive nature of its collection, testing for diazepam abuse in urine is also required for multiple reasons, including legal and workplace policies [8]. Studies have reported a great value in urine levels of metabolites of diazepam due to their longer detection window [9-14], but these studies used different animals or studied urinary kinetics for a short period of time and in a small number of subjects. More importantly, published detection methods for diazepam in urine always involve hydrolysis of the glucuronide metabolites and focus on diazepam as well as on its active metabolites nordiazepam, temazepam, and oxazepam. These methods have many limitations, including the possibility of incomplete hydrolysis due to competitive inhibition of the enzyme, reduction reactions of oxazepam or OG to nordiazepam, conversion of temazepam to diazepam during enzymatic hydrolysis, and decomposition of benzodiazepine molecules to benzophenones during acidcatalyzed hydrolysis [15].

Recently, diazepam and its glucuronide metabolites TG and OG were directly detected using a liquid chromatography-tandem mass spectrometry (LC-MS/MS) procedure in postmortem blood and urine of volunteers after the consumption of diazepam [15, 16]. This suggests that glucuronide compounds could also be easily detected. At the same time, the study reported a longer duration of detection of TG and OG in urine, thus extending the detection window of diazepam. Additionally, our previous study found that the glucuronide metabolites of diazepam can distinguish between poisoning in a living being versus postmortem exposure, which plays an important role in the identification of diazepam-related cases. However, to the best of our knowledge, no experimental studies of glucuronide metabolite kinetics in urine have been performed.

The purpose of this study was to investigate the pharmacokinetics of diazepam and its metabolites, including glucuronide compounds, in the urine of Chinese participants. Among the metabolites of diazepam, the amount of temazepam is the smallest and therefore least significant; thus, it was excluded from this study. After healthy Chinese volunteers ingested diazepam, we investigated the concentrations of diazepam and its metabolites (nordiazepam, TG, and OG) in urine for up to 15 days and established the basic pharmacokinetic information for diazepam and its metabolites, especially glucuronide metabolites, in urine.

\section{Methods}

\subsection{Materials}

Diazepam and oxazepam were obtained from the National Institute for the Control of Pharmaceutical and Biological Products (Beijing, China); nordiazepam $(1 \mathrm{mg} / \mathrm{mL})$, OG $(0.1 \mathrm{mg} / \mathrm{mL})$, and $\mathrm{TG}(0.1 \mathrm{mg} / \mathrm{mL})$ were purchased from Lipomed AG (Switzerland). The internal standard, nordiazepam-d5 $(1 \mathrm{mg} / \mathrm{mL})$, was obtained from Cerilliant (USA). All analytes were stored at $4{ }^{\circ} \mathrm{C}$. High-performance liquid chromatography (HPLC)-grade methanol and acetonitrile were obtained from RCI Labscan Ltd (Thailand), and ultrapure water was obtained from a water purification system (MilliQ Academic, USA). Solid-phase extraction (SPE) cartridges (Bond Elut C18, Part No: 12102099) were purchased from Agilent Technologies (USA).

\subsection{Volunteers}

Healthy female $(n=14)$ and male $(n=14)$ volunteers with no history of somatic or psychiatric illness, drinking, or medication were recruited into the study following their informed consent and comprehensive medical and psychological evaluations. Their median age was 24.4 years (range 22.5-26.5) and the average body mass index was $21.1 \mathrm{~kg} /$ $\mathrm{m}^{2}$ (range 17.0-35.0). The experiment was approved by the Institutional Animal Care and Use Committee of Shanxi Medical University (2014087) and all methods were performed in accordance with the relevant guidelines and regulations in China regarding the use of human subjects in scientific research.

\subsection{Biosamples}

Urine from each volunteer $(10 \mathrm{~mL})$ was collected before the experiment. After $12 \mathrm{~h}$ of fasting, the participants 
were administered one oral dose of $5 \mathrm{mg}$ of diazepam in the school infirmary, after which $10 \mathrm{~mL}$ of urine was collected at 1, 2, 4, 8, 12, and $24 \mathrm{~h}$ and 2, 3, 6, 12, and 15 days post-consumption timepoints. All samples were stored at $-20{ }^{\circ} \mathrm{C}$ until assayed. The volunteers were provided with standardized meals at 180 and $450 \mathrm{~min}$ after drug ingestion and allowed to return to their dormitories on campus during the study period.

\subsection{Sample Preparation and Analysis}

Diazepam and its main metabolites (nordiazepam, oxazepam, TG, and OG) in urine samples from each volunteer were extracted via SPE and analyzed by an LC-MS/MS method operated in a positive multiple response monitoring mode. The analysis was based on our published LC-MS/MS method for the measurement of diazepam and its metabolites in blood [17] and validated for the analysis of diazepam and its metabolites in urine.

\subsection{Pharmacokinetic Analysis}

The pharmacokinetic software DAS 3.0 (BioGuider Co., Shanghai) was used to calculate the maximum concentration $\left(C_{\max }\right)$, time to maximum concentration $\left(T_{\max }\right)$, elimination half-life $\left(t_{1 / 2 Z}\right)$, kidney clearance $(\mathrm{CLz} / F)$, and area under the curve $\left(\mathrm{AUC}_{\mathrm{t}}\right)$ according to the non-compartment model.

\subsection{Statistics}

All data are summarized using descriptive statistics. Arithmetic means and standard deviations of the pharmacokinetic parameters are provided.

\section{Results}

\subsection{Method Development and Validation}

All analytes were well separated and no endogenous peak coeluted with the analytes. The methods were also fully validated, as shown in Tables 1 and 2 . The limit of detection (LOD) in urine was $0.01 \mathrm{ng} / \mathrm{mL}$ for diazepam, nordiazepam and oxazepam, and the lower limit of linearity was $0.1 \mathrm{ng} / \mathrm{mL}$. The limit of quantitation (LOQ) and lower limit

Table 2 Standard calibration curves of diazepam and its metabolites in urine

\begin{tabular}{lllll}
\hline Compound & $r^{2}$ & $\begin{array}{l}\text { Linearity } \\
\text { range }(\mathrm{ng} / \\
\mathrm{mL})\end{array}$ & LOD $(\mathrm{ng} / \mathrm{mL})$ & LOQ $(\mathrm{ng} / \mathrm{mL})$ \\
\hline Diazepam & 0.9950 & $0.1-100$ & 0.01 & 0.05 \\
Nordiazepam & 0.9933 & $0.1-100$ & 0.01 & 0.05 \\
Oxazepam & 0.9912 & $0.1-100$ & 0.01 & 0.05 \\
TG & 0.9953 & $0.5-100$ & 0.5 & 0.5 \\
OG & 0.9923 & $5-100$ & 0.5 & 5 \\
\hline
\end{tabular}

$L O D$ limit of detection, $L O Q$ limit of quantification, $T G$ temazepam glucuronide, $O G$ oxazepam glucuronide

Table 1 Recovery, precision, and accuracy of diazepam and its metabolites in urine $(\bar{x} \pm \mathrm{S} ; n=3)$

\begin{tabular}{|c|c|c|c|c|c|c|c|}
\hline \multirow[t]{2}{*}{ Compound } & \multirow{2}{*}{$\begin{array}{l}\text { Spiked (ng/ } \\
\text { mL) }\end{array}$} & \multirow[t]{2}{*}{ Found (ng/mL) } & \multirow[t]{2}{*}{ Recovery (\%) } & \multicolumn{2}{|c|}{ Precision (\%) } & \multicolumn{2}{|c|}{ Accuracy (\%) } \\
\hline & & & & Inter-assay & Intra-assay & Inter-assay & Intra-assay \\
\hline \multirow[t]{3}{*}{ Diazepam } & 1 & $0.98 \pm 0.02$ & $98.00 \pm 2.00$ & 0.06 & 0.02 & 90.60 & 98.00 \\
\hline & 10 & $10.02 \pm 2.59$ & $100.20 \pm 25.90$ & 0.12 & 0.26 & 115.33 & 100.20 \\
\hline & 50 & $50.90 \pm 3.67$ & $101.80 \pm 7.34$ & 0.07 & 0.07 & 89.67 & 101.80 \\
\hline \multirow[t]{3}{*}{ Nordiazepam } & 1 & $0.93 \pm 0.14$ & $93.00 \pm 14.00$ & 0.07 & 0.15 & 76.60 & 93.00 \\
\hline & 10 & $8.60 \pm 1.82$ & $86.00 \pm 18.20$ & 0.14 & 0.21 & 98.60 & 86.00 \\
\hline & 50 & $49.40 \pm 0.85$ & $98.80 \pm 1.72$ & 0.09 & 0.02 & 102.07 & 98.00 \\
\hline \multirow[t]{3}{*}{ Oxazepam } & 1 & $0.94 \pm 0.15$ & $94.00 \pm 15.00$ & 0.04 & 0.16 & 83.90 & 94.00 \\
\hline & 10 & $10.03 \pm 1.73$ & $100.30 \pm 17.30$ & 0.06 & 0.17 & 82.80 & 100.30 \\
\hline & 50 & $50.13 \pm 3.00$ & $100.26 \pm 6.00$ & 0.04 & 0.06 & 96.13 & 100.26 \\
\hline \multirow[t]{3}{*}{ TG } & 1 & $1.14 \pm 0.20$ & $114.00 \pm 20.00$ & 0.06 & 0.18 & 128.50 & 114.00 \\
\hline & 10 & $11.87 \pm 0.15$ & $118.70 \pm 1.50$ & 0.05 & 0.01 & 118.00 & 118.70 \\
\hline & 50 & $50.63 \pm 6.6$ & $101.26 \pm 13.20$ & 0.08 & 0.13 & 106.67 & 101.26 \\
\hline \multirow[t]{3}{*}{ OG } & 5 & $4.96 \pm 1.28$ & $99.20 \pm 25.60$ & 0.04 & 0.12 & 129.62 & 99.20 \\
\hline & 10 & $10.98 \pm 1.56$ & $109.80 \pm 15.60$ & 0.10 & 0.14 & 113.67 & 109.80 \\
\hline & 50 & $46.57 \pm 3.36$ & $93.14 \pm 6.72$ & 0.16 & 0.07 & 100.93 & 93.14 \\
\hline
\end{tabular}

$T G$ temazepam glucuronide, $O G$ oxazepam glucuronide 
of linearity of TG in urine were $0.5 \mathrm{ng} / \mathrm{mL}$, and those of OG in urine were $5 \mathrm{ng} / \mathrm{mL}$.

\subsection{Pharmacokinetic Analysis}

After the volunteers consumed $5 \mathrm{mg}$ of diazepam, only diazepam, its main oxidative product nordiazepam, and glucuronide metabolites (TG, OG) were detected in urine samples, and the detection time window ranged from $1 \mathrm{~h}$ to 15 days, as shown in Table 3. However, as shown in Fig. 1, although diazepam and nordiazepam could still be detected after 15 days, their concentrations were much lower than those of TG and OG. In addition, as summarized in Fig. 1 and Table 4, following the consumption of $5 \mathrm{mg}$ of diazepam, diazepam reached its highest concentration $(2.30 \pm 1.36 \mathrm{ng} / \mathrm{mL})$ within $1 \mathrm{~h}$ and then declined gradually, and the metabolite nordiazepam reached its highest concentration $(0.96 \pm 0.47 \mathrm{ng} /$
$\mathrm{mL})$ at $72 \mathrm{~h}$. In comparing the concentration-time curve of diazepam and nordiazepam, it was found that the concentration of nordiazepam was obviously higher than that of diazepam $24 \mathrm{~h}$ after diazepam consumption. While the peak blood concentrations of TG $(114.4 \pm 152.15 \mathrm{ng} / \mathrm{mL})$ and OG $(71.95 \pm 83.20 \mathrm{ng} / \mathrm{mL})$ were observed at 48 and $72 \mathrm{~h}$, respectively, in comparing their concentration-time curve it was found that TG was at a higher concentration than OG until $72 \mathrm{~h}$ when their concentrations were reversed.

Based on the non-compartment model, the pharmacokinetic parameters of diazepam and its metabolites after oral administration of $5 \mathrm{mg}$ of diazepam were calculated and are shown in Table 5. It was found that diazepam could reach its peak concentration in urine $(2.38 \pm 1.26 \mathrm{ng} / \mathrm{mL})$ at $1.93 \pm 2.91 \mathrm{~h}$, and the metabolites nordiazepam, TG, and OG reached their peak concentrations $(1.17 \pm 0.40 \mathrm{ng} / \mathrm{mL}$, $145.61 \pm 136.98 \mathrm{ng} / \mathrm{mL}$, and $101.57 \pm 76.86 \mathrm{ng} / \mathrm{mL})$ at
Table 3 Detection time of analytes in urine $(\bar{x} \pm \mathrm{S} ; n=28)$

\begin{tabular}{lll}
\hline Compound & \multicolumn{1}{l}{ Urine } & \\
\cline { 2 - 3 } & Start, h (minimum-maximum) & End, h (minimum-maximum) \\
\hline Diazepam & $1.0 \pm 0.0(1.0-1.0)$ & $347.1 \pm 43.3(144.0-360.0)$ \\
Nordiazepam & $1.5 \pm 1.5(1.0-8.0)$ & $354.9 \pm 18.5(288.0-360.0)$ \\
TG & $1.1 \pm 0.6(1.0-4.0)$ & $336.9 \pm 66.8(144.0-360.0)$ \\
OG & $1.1 \pm 0.6(1.0-4.0)$ & $334.3 \pm 67.3(144.0-360.0)$ \\
\hline
\end{tabular}

$T G$ temazepam glucuronide, $O G$ oxazepam glucuronide

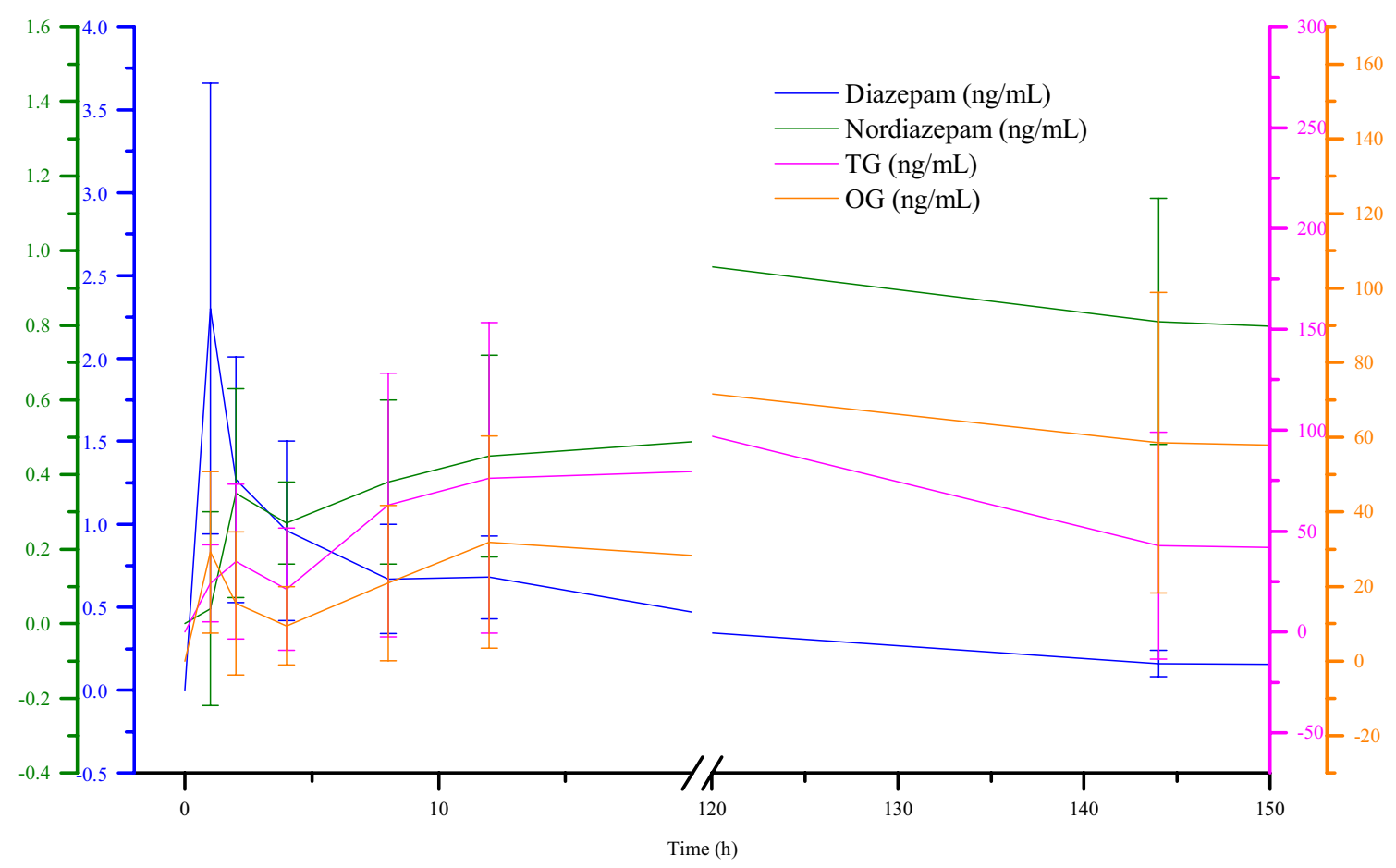

Fig. 1 Concentration-time curves of diazepam and its metabolites in urine. The left y-axis represents diazepam and nordiazepam, and the right y-axis represents TG and OG. Breaks are performed at 20 and $150 \mathrm{~h}$, respectively. $T G$ temazepam glucuronide, $O G$ oxazepam glucuronide 
Table 4 Concentrations of analytes in urine at 12 timepoints $(\bar{x} \pm \mathrm{S} ; n=28)$

\begin{tabular}{llllr}
\hline Time $(\mathrm{h})$ & Diazepam $(\mathrm{ng} / \mathrm{mL})$ & Nordiazepam $(\mathrm{ng} / \mathrm{mL})$ & TG $(\mathrm{ng} / \mathrm{mL})$ & \multicolumn{1}{c}{ OG $(\mathrm{ng} / \mathrm{mL})$} \\
\hline 0 & - & - & - & \multicolumn{1}{c}{-} \\
1 & $2.30 \pm 1.36$ & $0.04 \pm 0.26$ & $23.99 \pm 19.00$ & $29.16 \pm 21.65$ \\
2 & $1.27 \pm 0.74$ & $0.35 \pm 0.28$ & $34.83 \pm 38.27$ & $15.44 \pm 19.18$ \\
4 & $0.96 \pm 0.54$ & $0.27 \pm 0.11$ & $21.21 \pm 30.25$ & $9.44 \pm 10.45$ \\
8 & $0.67 \pm 0.33$ & $0.38 \pm 0.22$ & $62.81 \pm 65.38$ & $20.92 \pm 20.75$ \\
12 & $0.68 \pm 0.25$ & $0.45 \pm 0.27$ & $76.25 \pm 76.95$ & $31.85 \pm 28.45$ \\
24 & $0.46 \pm 0.26$ & $0.49 \pm 0.24$ & $79.83 \pm 138.13$ & $28.22 \pm 27.95$ \\
48 & $0.42 \pm 0.25$ & $0.71 \pm 0.36$ & $114.4 \pm 152.15$ & $47.54 \pm 28.49$ \\
72 & $0.35 \pm 0.20$ & $0.96 \pm 0.47$ & $98.13 \pm 115.53$ & $71.95 \pm 83.20$ \\
144 & $0.16 \pm 0.08$ & $0.81 \pm 0.33$ & $42.80 \pm 56.33$ & $58.33 \pm 40.30$ \\
288 & $0.07 \pm 0.05$ & $0.52 \pm 0.25$ & $21.25 \pm 30.39$ & $43.09 \pm 29.79$ \\
360 & $0.06 \pm 0.04$ & $0.51 \pm 0.27$ & $13.97 \pm 10.74$ & $51.32 \pm 40.90$ \\
\hline
\end{tabular}

$T G$ temazepam glucuronide, $O G$ oxazepam glucuronide

Table 5 Pharmacokinetic parameters of analytes in urine $(\bar{x} \pm \mathrm{S}$, minimum-maximum; $n=28)$

\begin{tabular}{|c|c|c|c|c|}
\hline Parameter & Diazepam & Nordiazepam & TG & OG \\
\hline $\operatorname{AUC}_{t}(\mu \mathrm{g} / \mathrm{L} * \mathrm{~h})$ & $77.86 \pm 29.43(36.82-155.49)$ & $\begin{array}{l}241.61 \pm 83.36(151.60- \\
505.31)\end{array}$ & $\begin{array}{r}16,202.12 \pm 17,348.38 \\
(2193.74-90,514.00)\end{array}$ & $\begin{array}{c}16,622.45 \pm 7844.85 \\
(2941.84-37,397.18)\end{array}$ \\
\hline$t_{1 / 2 \mathrm{Z}}(\mathrm{h})$ & $\begin{array}{l}119.58 \pm 114.59(38.27- \\
653.00)\end{array}$ & $\begin{array}{l}310.58 \pm 369.26(75.91- \\
1915.83)\end{array}$ & $\begin{array}{l}200.17 \pm 271.99(34.70- \\
1183.63)\end{array}$ & $\begin{array}{l}536.44 \pm 999.86(43.48- \\
4836.94)\end{array}$ \\
\hline$T_{\max }(\mathrm{h})$ & $1.93 \pm 2.91(1.00-12.00)$ & $100.21 \pm 70.07(2.00-288.00)$ & $41.14 \pm 29.95(8.00-144.00)$ & $\begin{array}{l}165.86 \pm 121.68(12.00- \\
360.00)\end{array}$ \\
\hline$C_{\max }(\mu \mathrm{g} / \mathrm{L})$ & $2.38 \pm 1.26(0.83-4.9)$ & $1.17 \pm 0.40(0.62-2.20)$ & $\begin{array}{l}145.61 \pm 136.98(35.70- \\
739.00)\end{array}$ & $101.57 \pm 76.86(26.80-451.00)$ \\
\hline $\mathrm{CLz} / F(\mathrm{~L} / \mathrm{h})$ & $65.77 \pm 25.42(30.43-131.50)$ & - & - & _- \\
\hline
\end{tabular}

$T G$ temazepam glucuronide, $O G$ oxazepam glucuronide, $A U C_{t}$ area under the curve, $t_{1 / 2 z}$ elimination half-life, $T_{\max }$ time to $C_{\max }, C_{\max }$ maximum concentration, $C L z / F$ clearance

$100.21 \pm 70.07 \mathrm{~h}, 41.14 \pm 29.95 \mathrm{~h}$, and $165.86 \pm 121.68 \mathrm{~h}$, respectively. The $\mathrm{t}_{1 / 2 \mathrm{z}}$ of diazepam, nordiazepam, TG, and OG was $119.58 \pm 114.59$ h, $310.58 \pm 369.26$ h, $200.17 \pm$ $271.99 \mathrm{~h}$, and $536.44 \pm 999.86 \mathrm{~h}$, respectively. The CLz/F of diazepam was $65.77 \pm 25.42 \mathrm{~L} / \mathrm{h}$; however, the CLz/F of the metabolites of diazepam (nordiazepam, TG, and OG) could not been calculated accurately because their initial dose was difficult to obtain.

\section{Discussion}

Urine is a conventional specimen with prospects for monitoring drugs of abuse in the workplace, clinical toxicology, criminal justice, and drug-driving programs. The analytical method used in this study has proven to be sensitive and accurate for the analysis of diazepam and its metabolites in urine. The lower LOD $(0.01 \mathrm{ng} / \mathrm{mL})$ and LOQ $(0.05 \mathrm{ng} / \mathrm{mL})$ achieved are not only particularly useful for quantifying the lower levels of diazepam and its oxidative metabolites presented in urine during pharmacokinetic investigation of diazepam as illustrated in Fig. 1, but also to some degree influence the detection times. The dose (5 $\mathrm{mg}$ ) used in the study was close to the therapeutic dose of the drug (5-10 mg), suggesting that the method might be suitable for monitoring driving under the influence of diazepam.

In this study, we detected lower concentrations of diazepam and nordiazepam and higher concentrations of TG and OG in the urine of volunteers after oral administration of diazepam $5 \mathrm{mg}$, and their detection time limit was more than 15 days. However, oxazepam could not be detected throughout the whole process, suggesting that oxazepam, in urine, might convert completely to OG. However, some studies have reported the presence of oxazepam in urine samples because of the difference in sample preparation, which hydrolyzes the $\mathrm{OG}$ in urine with $\beta$-glucuronidase to produce oxazepam $[10,12]$. Additionally, as mentioned in the introduction, oxazepam in urine has a much lower conversion rate to OG than temazepam to TG; thus, we speculated that both oxazepam and temazepam in urine might be conjugated completely with glucuronide, justifying the 
omission of temazepam as an analyte for drug monitoring purposes as well.

This study aimed to investigate the pharmacokinetics of diazepam and its metabolites in urine, especially for the glucuronide metabolites of diazepam. It was found that the concentration of nordiazepam was obviously higher than that of diazepam $24 \mathrm{~h}$ after diazepam consumption, and TG was at a higher concentration than OG until $72 \mathrm{~h}$, when their concentrations were reversed. This observation suggests that diazepam and its metabolites nordiazepam, TG, and OG, can act as specific markers of diazepam consumption and their relative concentrations can be used to eliminate the possibility of coadministration of diazepam with other benzodiazepines such as temazepam and oxazepam.

This study recruited a Chinese population of 28 individuals consuming $5 \mathrm{mg}$ of diazepam. In view of the greater individual difference in the metabolism of diazepam in human, which was reflected well in our data, a non-compartment model was used to calculate the pharmacokinetic parameters of diazepam and its metabolites in human urine. The models estimate that diazepam reached its peak concentration $(2.38 \pm 1.26 \mathrm{ng} / \mathrm{mL})$ in urine at $1.93 \mathrm{~h}$, and nordiazepam reached its peak concentration $(1.17 \pm 0.40 \mathrm{ng} / \mathrm{mL})$ in urine at 100.21 h. Umezawa et al. [13] administered a single $10 \mathrm{mg}$ oral dose of diazepam to five healthy subjects aged 28-48 years and reported that diazepam and nordiazepam reached their peak concentrations $(9.08 \pm 3.24 \mathrm{ng} / \mathrm{mL}$, $8.19 \pm 1.30 \mathrm{ng} / \mathrm{mL}$ ) at 1.5 and $12 \mathrm{~h}$, respectively. In another study [10], 11 European patients (nine male and two female volunteers aged $20-35$ years) received a $10 \mathrm{mg}$ oral dose of diazepam. The $T_{\max }$ of nordiazepam in urine was $11 \mathrm{~h}$, but the parent compound, diazepam, could not be detected. The great difference in those studies may be due to the influence of dosage, age, and interethnic differences [18-21]. Other influencing factors may include sex, liver disease, concurrent exposure to cytochrome P450 (CYP) inducers or inhibitors, and genetic variability [18, 22-28]. It is evident from this study that the pharmacokinetic parameters of diazepam and its metabolites vary significantly among individuals (Table 5). Smith-Kielland et al. [9] reported that the half-life of diazepam was 20-50 h and that of nordiazepam was 40-100 h. In contrast, in our study, the elimination half-lives of diazepam and nordiazepam in urine were 38.27-653.00 h and 75.91-1915.83 h, respectively. Furthermore, the longest detection period of diazepam varies significantly, with reported values ranging from 0 to $68 \mathrm{~h}[10$, 15], compared with $347.10 \pm 43.30 \mathrm{~h}$ (ranging from 144.00 to $360 \mathrm{~h}$ ) observed in this study. The longest detection period of nordiazepam varies from 1.50 to $252.00 \mathrm{~h}[10,13]$, compared with $354.90 \pm 18.50 \mathrm{~h}(288.00-360 \mathrm{~h})$ observed in this study, indicating a significant difference.

TG and OG are phase II metabolites of diazepam; there have been studies stating that the glucuronide metabolites of diazepam have higher concentrations and longer detection windows in urine $[15,29]$. However, none of the pharmacokinetic parameters of diazepam glucuronide metabolites are currently available. This study first evaluated the kinetic disposition of glucuronide metabolites of diazepam in the urine of a Chinese population. It was found that the levels of TG and OG in urine were much higher than those of diazepam and its oxidation products, and the half-life, especially for OG (536.44 $\pm 999.86 \mathrm{~h}$ ), was longer than that of diazepam and its other metabolites, which reminded us that it would be feasible to identify the ingestion of diazepam based on the pharmacokinetic results of the glucuronide metabolites in urine, even after a much longer time. Therefore, although there were significant individual differences, the results could be used to identify drivers under the influence of diazepam using a sensitive testing method, especially in retrospective cases.

As mentioned above, diazepam metabolism is influenced by many factors. Among these factors, genetic differences are considered one of the major contributors to the pharmacokinetic variations of diazepam [20]. CYP2C19 is a CYP isozyme responsible for $N$-demethylation of diazepam to form nordiazepam during the metabolic process, and its polymorphism plays a major role in the observed metabolic differences [30, 31]. CYP2C19 m1/m1 and CYP2C19 wt/ $\mathrm{m} 1$ are two CYP2C19 phenotypes, in which the former is a poor metabolizer and the latter is an extensive metabolizer. Qin [26] reported a significant difference in the pharmacokinetic behavior of diazepam and nordiazepam between the two groups. In addition, Smith-Kielland et al. [9] reported that the existence of poor and extensive metabolizers of diazepam and nordiazepam can account for the wide range of half-lives observed.

The strength of the present study is the experimental design and the collection of samples to study the pharmacokinetics of diazepam and its metabolites, including glucuronide compounds, in the urine of 28 Chinese volunteers for a relatively long time period. The limitation of the present study is that CYP phenotyping was not performed in advance. In addition, the analyte concentration in urine was not corrected for urinary creatinine concentration, which might be another important factor accounting for the large individual differences observed. Thus, further studies are needed to investigate the influence of the CYP phenotype and urinary creatinine concentration on the pharmacokinetics of diazepam and its metabolites in the urine of the Chinese population.

\section{Conclusion}

This study demonstrated the pharmacokinetics of diazepam and its metabolites, including glucuronide compounds, in the urine of Chinese volunteers after a therapeutic dose. 
Although there were significant individual differences, these results would be useful for law enforcement officers to analyze such cases.

Acknowledgments The authors would like to thank Yi He, Xinxin Ren, and Guan-feng Cui from the Ministry of Public Security Material Evidence Identification Center for their help. They would also like to thank Prof. Zhongyuan Guo for his help in the design process of the study, and thank Editage (www.editage.cn) for English language editing.

\section{Declarations}

Funding The controlled study belonged to the National Nature Science Foundation of China (NSFC) (81172906), National Key Technology R \& D Program of China (2007BAK26B05 and 2012BAK02B02), and the National Science and Technology Special Project Work (SQ2015FYJ010051).

Conflict of interest Le-le Wang, Xin-xin Ren, Yi He, Guan-feng Cui, Jia-jia Liu, Juan Jia, Jie Cao, Yao Liu, Bin Cong, Zhi-wen Wei, and Ke-ming Yun declare they have no conflicts of interest in relation to this work.

Availability of data and material All data generated during the study appear in the submitted article, and all material used during the study is available as per the details provided in the submitted article.

Code availability Not applicable.

Author contributions Yao Liu, Bin Cong, Zhi-wen Wei and Ke-ming Yun designed the research; Le-le Wang, Xin-xin Ren, Guan-feng Cui and Yi He performed most of the experiments and conducted the studies; and Juan Jia and Jie Cao analyzed the data. Le-le Wang and Jia-jia Liu prepared the manuscript and edited the paper.

Ethics approval This study was approved by the Committee of Medical Ethics of Shanxi Medical University (2014087). All methods were performed in accordance with the relevant guidelines and regulations in China regarding the use of human subjects in scientific research.

Consent to participate All subjects provided written informed consent prior to screening.

Consent for publication All authors read and approved the manuscript.

Open Access This article is licensed under a Creative Commons Attribution-NonCommercial 4.0 International License, which permits any non-commercial use, sharing, adaptation, distribution and reproduction in any medium or format, as long as you give appropriate credit to the original author(s) and the source, provide a link to the Creative Commons licence, and indicate if changes were made. The images or other third party material in this article are included in the article's Creative Commons licence, unless indicated otherwise in a credit line to the material. If material is not included in the article's Creative Commons licence and your intended use is not permitted by statutory regulation or exceeds the permitted use, you will need to obtain permission directly from the copyright holder. To view a copy of this licence, visit http://creativecommons.org/licenses/by-nc/4.0/.

\section{References}

1. Woods JH, Katz JL, Winger G. Benzodiazepines: use, abuse, and consequences. Pharmacol Rev. 1992;44:151-347.

2. Martin IL. The benzodiazepines and their receptors: 25 years of progress. Neuropharmacology. 1987;26:957-70.

3. Lim JY, Lee DH. Characteristics of drugs ingested for suicide attempts in the elderly. J Korean Med Sci. 2018;33:e86.

4. Li F, Chen Y, Gong B, Ruan L, Li H, Tang W, Liu W, Ynag H. Investigation on drug use and driving of patients with mental disorders. J Clin Psychiatr. 2016:26(01):51.

5. Lugoboni F, Morbioli L. Benzodiazepine abuse in the attention deficit hyperactivity disorder. A case report. J Clin Psychopharm. 2018;38:402-4.

6. Costa E. The benzodiazepines: from molecular biology to clinical practice. New York: Raven Press; 1983.

7. Dinis-Oliveira RJ. Metabolic profile of oxazepam and related benzodiazepines: clinical and forensic aspects. Drug Metab Rev. 2017;49:451-63.

8. Lennestal R, Lakso HA, Nilsson M, Mjorndal T. Urine monitoring of diazepam abuse- new intake or not? J Anal Toxicol. 2008;32:402-7.

9. Smith-Kielland A, Skuterud B, Olsen KM, Morland J. Urinary excretion of diazepam metabolites in healthy volunteers and drug users. Scand J Clin Lab Invest. 2001;61:237-46.

10. Temte V, Kjeldstadli K, Bruun LD, Birdal M, Bachs L, Karinen R, et al. An experimental study of diazepam and alprazolam kinetics in urine and oral fluid following single oral doses. J Anal Toxicol. 2019;43:104-11.

11. Marland A, Sarkar P, Leavitt R. The urinary elimination profiles of diazepam and its metabolites, nordiazepam, temazepam, and oxazepam, in the Equine after a 10-mg intramuscular dose. J Anal Toxicol. 1999;23:29-34.

12. Chiba K, Horii H, Chiba T, Kato Y, Hirano T, Ishizaki T. Development and preliminary application of high-performance liquid chromatographic assay of urinary metabolites of diazepam in humans. J Chromatogr B Biomed Appl. 1995;668:77-84.

13. Umezawa H, Lee XP, Arima Y, Hasegawa C, Marumo A, Kumazawa T, et al. Determination of diazepam and its metabolites in human urine by liquid chromatography/tandem mass spectrometry using a hydrophilic polymer column. Rapid Commun Mass Spectrom. 2008;22:2333-41.

14. Schenk I, Machnik M, Broussou D, Meuly A, Roques BB, Lallemand E, et al. Kinetic disposition of diazepam and its metabolites after intravenous administration of diazepam in the horse: relevance for doping control. J Vet Pharmacol Ther. 2021;44:733-44.

15. Wang X, Wang R, Zhang Y, Liang C, Ye H, Cao F, et al. Extending the detection window of diazepam by directly analyzing its glucuronide metabolites in human urine using liquid chromatographytandem mass spectrometry. J Chromatogr A. 2012;1268:29-34.

16. Wang R, Wang X, Liang C, Ni C, Xiong L, Rao Y, et al. Direct determination of diazepam and its glucuronide metabolites in human whole blood by $\mu$ Elution solid-phase extraction and liquid chromatography-tandem mass spectrometry. Forensic Sci Int. 2013;233:304-11.

17. Wang L, Ren X, He Y, Cui G, Wei Z, Jia J, et al. Study on the pharmacokinetics of diazepam and its metabolites in blood of Chinese people. Eur J Drug Metab Pharmacokinet. 2020;45:477-85.

18. Jones AW, Holmgren A, Holmgren P. High concentrations of diazepam and nordiazepam in blood of impaired drivers: association with age, gender and spectrum of other drugs present. Forensic Sci Int. 2004;146:1-07.

19. Friedman H, Greenblatt DJ, Peters GR, Metzler CM, Charlton MD, Harmatz JS, et al. Pharmacokinetics and pharmacodynamics 
of oral diazepam: effect of dose, plasma concentration, and time. Clin Pharmacol Ther. 1992;52:139-50.

20. Zhang Y, Reviriego J, Lou YQ, Sjöqvist F, Bertilsson L. Diazepam metabolism in native Chinese poor and extensive hydroxylators of S-mephenytoin: Interethnic differences in comparison with White subjects. Clin Pharmacol Ther. 1990;48:496-502.

21. Marcucci F, Guaitani A, Kvetina J, Mussini E, Garattini S. Species difference in diazepam metabolism and anticonvulsant effect. Eur J Pharmacol. 1968;4:467-70.

22. Gershkovich P, Wasan KM, Ribeyre C, Ibrahim F, Mcneill JH. Effect of variations in treatment regime and liver cirrhosis on exposure to benzodiazepines during treatment of alcohol withdrawal syndrome. Drugs Context. 2015;4:1-6.

23. Peng J, Liu W. Research progress in the effect of CYP2C19 gene polymorphisms on drug metabolism. J Pharm Pract. 2015;33:508-12.

24. Sakai N, Ishizuka M. Impact of rat P450 genetic polymorphism on diazepam metabolism. Expert Opin Drug Metab Toxicol. 2009;5:1421-33.

25. Kosuge K, Jun Y, Watanabe H, Kimura M, Nishimoto M, Ishizaki T, et al. Effects of CYP3A4 inhibition by diltiazem on pharmacokinetics and dynamics of diazepam in relation to CYP2C19 genotype status. Drug Metab Dispos. 2001;29:1284-9.

26. Qin X, Zhang X, Zhou H. Difference of metabolism of diazepam between two groups of genotype. J Changzhi Med Coll. 1999;03:166-8.

27. Özdemir M, Aktan Y, Boydaĝ BS, Cingi MI, Musmul A. Interaction between grapefruit juice and diazepam in humans. Eur J Drug Metab Pharmacokinet. 1998;23:55-9.

28. Perucca E, Gatti G, Cipolla G, Spina E, Barel S, Soback S, et al. Inhibition of diazepam metabolism by fluvoxamine: a pharmacokinetic study in normal volunteers. Clin Pharmacol Ther. 1994;56:471-6.

29. McBurney L. Detection of diazepam and determination of time of ingestion. J Can Soc Forensic Sci. 1981;14:152-64.

30. Fukasawa T, Suzuki A, Otani K. Effects of genetic polymorphism of cytochrome P450 enzymes on the pharmacokinetics of benzodiazepines. J Clin Pharm Ther. 2007;32:333-41.

31. Inomata $S$, Nagashima A, Itagaki F, Homma M, Nishimura $M$, Osaka Y, et al. CYP2C19 genotype affects diazepam pharmacokinetics and emergence from general anesthesia. Clin Pharmacol Ther. 2005;78:647-55. 